\section{Atomic Weight of Silver}

SILver is an important secondary standard of atomic weights, the values of these for many elements having been determined with reference to silver. The natural element contains two isotopes, 107 and 109, and the average atomic weight has been accepted as 107.880 , on the chemical scale. A mass-spectrometer investigation by W. R. Shields, D. N. Craig and V. H. Diebeler, of the Bureau of Standards, Washington, is reported in the October issue of the Journal of the American Chemical Society (p. 5033). It was found that no variation in abundance ratio occurred in six specimens of natural silver, but a seventh, from Cobalt, Ontario, showed a significant deviation. The values of the atomic weight found were, on the physical scale $\left({ }^{16} \mathrm{O}=16\right) 107.9028 \pm$ 0.0013 , on the chemical scale $(O=16) 107.8731 \pm$ 0.0020 , and on the proposed unified scale $\left({ }^{12} \mathrm{C}=12\right)$ $107 \cdot 8685 \pm 0.0013$. It is seen that the chemical value differs appreciably from $107 \cdot 880$.

\section{Binocular Depth Ferception}

ONE of the difficulties in studying depth perception is to isolate the different factors that contribute to the three-dimensional effect, and in particular to separate the binocular from the monocular cues. A highly original method of achieving this separation has been developed at the Bell Telephone Laboratories by B. Julesz, and, under the heading "Binocular Depth Perception of Computer-Generated Patterns", the subject is discussed in a recent issue of The Bell System Technical Journal $(39,1125 ; 1960)$. In this method the two pictures to be viewed in a stereoscope consist of a random arrangement of black, white and grey dots. These two micropatterns are similar in dot distribution except for a central area where, for example, a square-shaped rogion is given a uniform horizontal displacement. Each pattern by itself has a completely random appearance, but when viewed in a stereoscope, the parallax produced by the lateral displacement causes the central square region to appear either in front of or behind the surround, depending on the direction of displacement. Several interesting features emerge from this method of presentation in which monocular cues are oliminated. For example, several seconds or even minutes may elapse before the depth effect is perceived, presumably while the eye and brain are searching the pattern and assimilating the information being presented to the subject. When the viewing is repeated, the perception-time may be shortened as the process of learning facilitates recognition of the pattern. The effect of varying the contrast of the pattern, its sharpness, different perturbations of the pattern and the introduction of a monocularly recognizable pattern have all been studied to see how far the depth effect is enhanced, although just what is meant by depth enhancement is not immediately obvious.

\section{The Night Sky in January}

FULL moon occurs on Jan. 1d. 23h. 06m. U.T., new moon on Jan. 16d. $21 \mathrm{~h} .30 \mathrm{~m}$. and full moon on Jan. 31d. $18 \mathrm{~h} .47 \mathrm{~m}$. The following conjunctions with the Moon take place: Jan. 1d. 17h., Mars $8^{\circ} \mathrm{N}$.; Jan. 20d. 05h., Venus $0 \cdot 6^{\circ}$ N. ; Jan. 26d. 13h., Aldebaran $0 \cdot 3^{\circ}$ S. ; Jan. 28d. 07h., Mars $8^{\circ} \mathrm{N}$. Morcury will be visible as an evening star near the end of the month, setting about one and a half hours after the Sun. Venus is an evening star, and is favourably placed for observation. Venus sets at $20 \mathrm{~h} .00 \mathrm{~m}$., $20 \mathrm{~h}$. $35 \mathrm{~m}$. and $21 \mathrm{~h} .15 \mathrm{~m}$. on January 1, 15 and 31 , respectively, about four hours after the Sun. During the month its distance from the Earth decreases from 83 to 63 million miles, the visible portion of the apparent disk from $0 \cdot 639$ to $0 \cdot 499$, and its stellar magnitude from $-3 \cdot 7$ to $-4 \cdot 1$. Mars is above the horizon all night on January 1 , and sets at $7 \mathrm{~h} .10 \mathrm{~m}$. and $6 \mathrm{~h}$. $5 \mathrm{~m}$. on January 15 and 31 , respectively. Mars is very conveniently situated for observation. It is at a distance of $6 \mathrm{I}$ million miles from the Earth on January 15, and its stellar magnitude is $-1 \cdot 0$. Jupiter and Saturn are too close to the Sun for observation. Occultations of stars brighter than magnitude 6 are as follows, observations being made at Greenwich : Jan. 7 d. 5 h. $09 \cdot 8 \mathrm{~m}$., 59 Leo. $(R)$; Jan. $24 \mathrm{~d}$. $19 \mathrm{~h}$. $57 \cdot 2 \mathrm{~m} .,+11^{\circ} 445(D)$; Jan. 26d. $23 \mathrm{~h} .59 \cdot 6 \mathrm{~m} ., 318 \mathrm{~B}$. Tau. $(D) . \quad D$ and $R$ refer to disappearance and reappearance, respectively. The Quadrantid meteors are active on January 3 , but conditions are unfavourable for observation. The Earth is at perihelion on January 2 , its distance from the Sun being $91 \cdot 4$ million miles.

\section{Announcements}

Dr. Dethev Bronk, president of the Rockefeller Institute, has been elected an honorary momber of the Brazilian Academy of Science and has been awarded an honorary doctorate of the University of Brazil.

Dr. Amyand David Buckingham has been awarded the Harrison Memorial Prize for 1959 in consideration of his work on solvent effects on molecular spectra and the theory of pressure-induced spectra. Dr. Buckingham is at present in the Department of Inorganic Chemistry, University of Oxford.

Dr. H. Harold Hume, of Gainsville, Florida, has been awarded a gold Veitch Memorial Medal by the Council of the Royal Horticultural Society for his work on horticulture and in particular for his work in connexion with camellias.

THE Systomatics Association are arranging a meeting on "Multivariate Methods in Taxonomy" to be held in the Department of Botany, the University of Southampton, during April 24-25, 1961. Further information can be obtained from Dr. J. M. Lambert, Department of Botany, University of Southampton.

"RAdio Techniques and Space Research" will be the theme of next year's British Institution of Radio Engineers' Convention which will take place during July 5-9, 1961, at the University of Oxford. The Convention will contain at least six sessions, provisionally entitled: "Review of the Role of Radio Techniques in Space Research"; "Satellite Engineering Problems"; "Extra-terrestrial Measurements"; "Telemetry"; "Techniques in Radio Astronomy"; "Satellites in Terrestrial Communications". The Convention Committee has invited offers for papers, and these should be addressed to the British Institution of Radio Engineers, 9 Bedford Squaro, London, W.C.1.

The Chemical Society, Burlington House, London, W.1, has published "Periodicals in the Chemical Society Library", giving the complete periodical holdings in the Library (Pp. 48. London: The Chemical Society, 1960. 5s. post paid). This will be useful not only to members of the Society but also to librarians and users of chemical literature generally. 